\title{
Transmission, Occupationally Related
}

National Cancer Institute

\section{Source}

National Cancer Institute. Transmission, Occupationally Related. NCI Thesaurus. Code C19082.

Passage or transfer, as of a disease, to a recipient individual within or due to occupational circumstances. $(\mathrm{NCl})$ 